Research Article

\title{
Research on the Energy-Saving Design Path of Rural Farmhouses under the Background of Ecological Livability
}

\author{
Jingyuan Shi ${ }^{1}$ and Qiuna $\mathrm{Li} \mathbb{( i )}^{2}$ \\ ${ }^{1}$ College of Architecture and Urban Planning of Chongqing, Jiaotong University, Yuzhong District, Chongqing 400074, China \\ ${ }^{2}$ Chongqing College of Architecture and Technology, Shapingba District, Chongqing 401331, China \\ Correspondence should be addressed to Qiuna Li; 990201900031@cqjtu.edu.cn
}

Received 19 June 2021; Revised 5 August 2021; Accepted 14 August 2021; Published 7 September 2021

Academic Editor: Wei Liu

Copyright (c) 2021 Jingyuan Shi and Qiuna Li. This is an open access article distributed under the Creative Commons Attribution License, which permits unrestricted use, distribution, and reproduction in any medium, provided the original work is properly cited.

\begin{abstract}
Different from the state of large-scale energy use and concentrated energy conservation in urban areas, the state of energy use and energy conservation in rural areas has its own characteristics and typical problems. Rural areas have been concentrated on the multiple differences in economic, social, and construction characteristics such as mountain and peace dam topography, natural and artificial construction, developed and underdeveloped, rapid urban development, and relatively backward rural development. It has practical problems that need to be solved urgently, such as the "insufficient savings" in the construction of farmhouses and the "insufficient open source" of clean energy applications. The discussion will be conducted from three aspects: the planning and layout design of rural houses in Chongqing, the performance of the enclosure structure of rural houses in key seasons, and the application of renewable clean energy in rural houses. Then put forward is the energy-saving design path of Chongqing farmhouse. It aims to improve the indoor and outdoor thermal environment of farmhouses, saving heating energy consumption in winter and air-conditioning energy consumption in summer and effectively benefit users to use renewable energy such as biogas, straw, and solar energy. Finally, explore the adaptability between the design methods of farmhouses and the local characteristics of Chongqing's rural areas. In the work of Chongqing Design Going to the Countryside, we create a contemporary farmhouse case that is not only energy-saving but also has good indoor and outdoor space quality. It also provides a reference for the energy-saving design of farmhouses in Chongqing and other regions in China.
\end{abstract}

\section{Introduction}

The farmhouse is the basic unit of rural residential environment and is the daily living space for rural residents to rest and prepare for work. Its construction process has particularity and complexity. It not only contains part of the traditional ecological adaptation wisdom, but also reflects the conflicts between the ecological planning and construction process and the ecological environment. The core problem of rural farmhouses is that the state of planning and construction is still at a relatively low level on the ecological level. It is necessary to carry out appropriate ecological guidance and improvement work in light of the regional characteristics and actual conditions of rural areas.
Compared with the consensus on urban energy consumption, the energy consumption of the rural construction environment is actually not small. Due to the expansion of the construction base and the insufficient energy conservation of the enclosure structure, the rural farmhouses have caused serious energy waste. In 2018, rural residential buildings accounted for $14 \%$ of the energy consumption for civil building construction. According to China's Annual Development Research Report on Building Energy Conservation 2020 (Rural Housing Special), the total energy consumption of rural farmhouses in 2020 will reach 311 million tce (Figure 1). Chongqing's natural environment has inherent advantages in ecological resources. And in the process of traditional village construction, the ecological adaptability of the mountain environment will be considered 


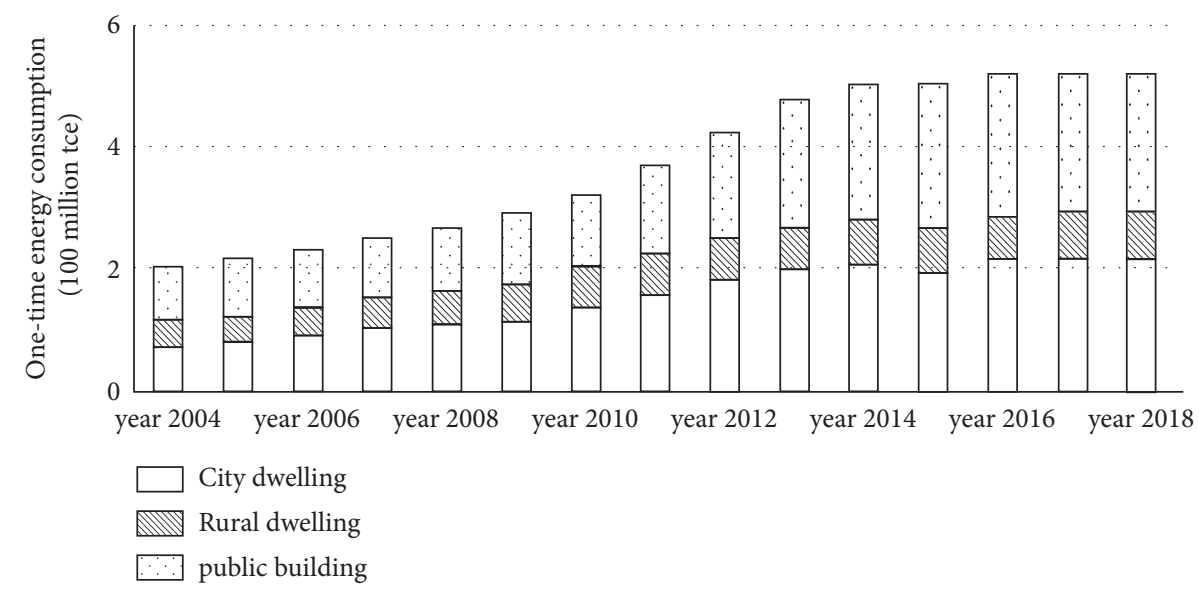

FIgURE 1: China's civil building construction energy consumption (2004-2018). Data source: estimated by the Building Energy Research Center of Tsinghua University.

spontaneously. However, in recent years, there has been a lack of ecological awareness in the process of rural planning and construction in Chongqing. The closedness of rural farmhouses is generally weak. Its energy-saving effect and thermal comfort are obviously different from those of urban houses. Take power consumption as an example. The electricity consumption per unit construction area in rural areas in Chongqing is $27.7 \mathrm{~kW} \cdot \mathrm{h} / \mathrm{m}^{2}$. It is significantly higher than the average electricity consumption level of $17.6 \mathrm{~kW} \cdot \mathrm{h} /$ $\mathrm{m}^{2}$ for urban residential buildings in the Yangtze River Basin. In addition, energy utilization is insufficient, and clean energy utilization is insufficient. These are all typical problems in Chongqing's farmhouses [1, 2].

In recent years, the research on energy conservation of rural residential buildings in China has been focused on the life cycle analysis of rural residential energy consumption ( $\mathrm{Li}$ Rong, 2006); the energy consumption status and optimization strategy of Henan rural housing (Lumeijun, Zhangshaowei, 2010); analysis of the influence of indoor thermal environment and energy consumption on rural residential buildings in cold areas (Donghailong, 2010); the indoor thermal environment index of rural residential buildings in Northwest China in winter (Zhuyiyun, Liujiaping, 2010); the three directions of applying ecological energy-saving technology in rural houses in Chongqing include optimization of building envelope structure, building partition and indoor environment, and improvement of energy-saving of ecological building equipment to rural houses (Guanjian, 2017); and the application of biomass energy and solar energy resources is the basis of rural renewable energy technology. The application possibility of solar water heater, solar stove, and biomass energy heating furnace technology is proposed (through investigation and monitoring of biogas project in some rural areas of Chongqing, the paper puts forward the cooking lighting mode suitable for scattered farming of farmers and hot water heating mode suitable for centralized cultivation of residential areas). Based on previous research, this paper proposes innovative research focusing on rural areas of Chongqing, further discovering the scientific problems of energy use and saving of rural housing and summarizing the possible path of energy conservation of agricultural houses from the perspective of architectural design [3, 4].

\section{Energy Problems in Chongqing's Farmhouses}

2.1. Insufficient Throttling-Energy-Saving Problem of Farmhouse Construction. The planning, design, and construction of urban residential buildings in Chongqing are in compliance with relevant energy-saving standards. And by improving the energy saving efficiency of air-conditioning, refrigeration, heating, and heating equipment, reduce all kinds of energy consumption in the operation of air-conditioning, lighting, hot water, and other equipment. At the same time, insufficient attention has been paid to energy conservation in the planning and construction of rural farmhouses. In the mid-1980s, rural areas in Chongqing began to be electrified, and electrical appliances such as lighting fixtures entered farmhouses. In recent years, with the improvement of villagers' living standards, high-power household appliances have become popular. According to statistics, in 2017, on average, one in two households in Chongqing rural areas used air conditioners and water heaters. The fan usage rate is as high as $90 \%$. In the survey of villages such as Zhongliang Town in Shapingba District, Yudong Town in Banan District, and Luohuang Town in Jiangjin District, it was found that every household had 2 to 4 air conditioners. Some farmers have as many as 6-8. The utilization rate of heating equipment such as electric heaters and water heaters has also continued to increase [5].

Rural houses in Chongqing are mostly brick-concrete structures. There is no energy-saving control in design and construction. This situation is reflected in the fact that the walls and other enclosure structures are basically not treated with thermal insulation and have poor thermal performance. The ratio of the figure coefficient of the farmhouse to the area of the window and wall is too large without control. The air tightness of door and window components such as singlelayer ordinary glass windows is poor. No thermal bridge condensation treatment has been performed. Poor indoor 
thermal environment in winter and summer leads to highpower consumption of air conditioners and so on. Therefore, only by paying attention to the energy conservation in the planning and construction of rural houses in Chongqing, can the total energy consumption be effectively reduced and energy "saving" can be achieved.

\subsection{Insufficient Open Source-The Application of Clean} Energy. The effective use of clean energy such as household biogas, solar energy, and straw can broaden energy sources while saving traditional energy sources such as electricity and realize the "open source" of energy problems in rural areas of Chongqing. The survey found that the clean energy application of Chongqing's farmhouses presents the following problems [6].

2.2.1. Household Biogas Is Difficult to Construct, with Low Efficiency and Simple Application. Household biogas digesters were once the main content of Chongqing's rural clean energy construction. In 2015, Chongqing has built more than 5,700 biogas project villages, with a total of 1.557 million users. But now the construction of household biogas has cooled down. Except for Wanzhou, Wulong, and other places, many districts and counties no longer even use it. According to the survey, it takes about 10 man-days to complete a household biogas digester. In recent years, most of the young and middle-aged laborers in Chongqing's rural areas have gone out to work, and left-behind farmers are unable to build pools. In terms of cost, Chongqing's rural areas are mostly in typical mountainous areas with many mountains and steep slopes. The transportation is inconvenient and the economy is relatively backward. Some farmers and farms gave up building ponds due to financial difficulties. In addition, there are problems: the biogas application system is not perfect, the efficiency of biogas production is low, the development of centralized biogas is slow, the operation of follow-up service outlets is weak, the responsible organization is lacking, and the management work is difficult to carry out, the single purpose of biogas which is only used for cooking and lighting, and so on.

\subsubsection{Pollution Caused by Straw Burning-Potential Re-} sources Are Not Utilized. Straw is a common agricultural waste and one of the main energy sources in rural areas of Chongqing. Most of the current disposal measures are used for fuel energy or incineration. However, the thermal efficiency of direct combustion is very low. The emission of a large amount of smoke and ash will make the rural living environment worse. It also causes a series of problems such as waste of resources, damage to farmers' health, and impact on traffic safety. According to incomplete statistics, straw and firewood accounted for $83 \%$ of Chongqing's rural energy use. The thermal efficiency of direct combustion is only $10 \%-20 \%$, being inefficient and uneconomical [7].
2.2.3. Misunderstandings Exist in Solar Energy Applications, and the Types of Applications Are Not Sufficient. Chongqing has more rainy weather and not enough sunshine. On the surface, there is a misunderstanding that solar technology cannot be used at all. However, during the investigation, it was discovered that there is actually the possibility of solar energy utilization in various districts and counties. For example, rural solar energy applications in Yongchuan District are more common, and more than half of the residents choose to use solar energy equipment. Therefore, the possibility of solar energy application should be sorted out and analyzed according to the regional characteristics of Chongqing. In addition, we need to summarize the different types of solar energy applications and implement suitable equipment such as solar water heaters and solar street lights in suitable areas to effectively use sunshine, an inexhaustible clean energy [8].

2.3. Summary of the Problem. All the above problems show that the rural houses in Chongqing area exist because of their actual characteristics. It is even more necessary to introduce ecological methods and strategies in planning and construction to truly achieve the ultimate goal of rural ecological livability. Therefore, it is urgent to consider the ecological problems of Chongqing's farmhouses in terms of saving resources, protecting the environment, reducing residential energy consumption, and improving residential comfort, so as to maintain ecological adaptability to the natural environment. The basic attitude of improving the living standards of villagers and optimizing the rural living environment should be followed, guided by ecological thinking, supported by ecological laws, and ecological design as a path to promote the dependence and coordination between people, architecture, and the environment.

The energy-saving design path of the farmhouse is to improve the energy efficiency of the farmhouse. On the premise of ensuring a comfortable living environment for rural residents, plan and guide measures for rational utilization and effective energy saving. Different from the state of large-scale and concentrated energy use in urban areas, the state of energy use and energy conservation in rural areas has its own characteristics and typical problems. Based on the actual situation, the energy utilization links involved in rural farmhouses in Chongqing are mainly embodied in three aspects: overall layout planning of farmhouses; the performance of the enclosure structure of farmhouses in the two key seasons of winter and summer; and the application of renewable clean energy in farmhouses. The specific energysaving design path can be developed from some key points, for example, the rational layout of the overall planning environment of the farmhouse; the construction process of the farmhouse, especially the optimization and improvement of the enclosure structure; and the suitable application method of rural renewable energy, etc. 


\section{Energy-Saving Planning of Farmhouses}

3.1. The Impact of Wind Direction on Farmhouse Energy Consumption and Reasonable Planning. The summer wind direction has a greater impact on the natural ventilation of farmhouses. Its effective organization can enhance the degree of air convection in the farmhouse and accelerate the heat exchange inside and outside the farmhouse at night. In this way, the purpose of saving energy for air-conditioning is achieved. The direction of the winter wind will bring heat loss to the farmhouse and will also affect the total amount of energy used for heating. Therefore, the reasonable design of the wind direction is very necessary.

The wind direction design mainly includes two aspects: on the one hand, the farmhouse can achieve good ventilation through the reasonable organization of spacing and layout; on the other hand, the direction is conducive to the smooth entry of the summer wind and avoid the invasion of winter wind. Through a good natural ventilation organization, the cooling and heating energy consumption of farmhouses can be effectively reduced [9].

\subsection{The Impact of Farmhouse Layout on Energy Consumption} and Reasonable Planning. The overall layout of rural farmhouses in Chongqing generally adopts determinant, staggered, oblique, peripheral, and free style. The following principles should be followed in the layout: the layout of the farmhouse community should be conducive to ventilation in summer and shelter from wind in winter. Meet the requirements of sunshine, environmental vision, and hygiene standards through suitable farmhouse spacing. In addition, the layout of farmhouses can also make full use of the surrounding water bodies, greening, and other natural resources to form a microclimate environment with good ecological benefits.

In the design of the plan, elevation, section, doors, and windows of rural farmhouses, consideration should be given to making them conducive to natural ventilation and natural lighting, avoid rain, snow, and wind, and effectively reduce energy consumption. The main rooms should be arranged in the south or south as far as possible. Make full use of the winter sun for heating and avoid direct sunlight in summer. Controlling the room area can effectively save energy for cooling or heating. The exhaust vents of the kitchen and bathroom spaces should be ventilated to avoid backflow and oil fume pollution. Controlling the depth of the daylighting room within 6 meters can effectively save lighting and daylighting energy.

3.3. The Impact of Farmhouse Orientation on Energy Consumption and Reasonable Planning. In winter, compare the same farmhouses. The east-west farmhouses consume about $5.5 \%$ more energy than the north-south farmhouses. The heat gained by solar radiation and the heat loss by air penetration through the gaps between doors and windows are also related to the orientation of the building. Therefore, in order to reduce building energy consumption in winter, the orientation of farmhouses should be north-south or close to north-south. The main facade should avoid the prevailing wind direction in winter. In summer, air-conditioning energy consumption is closely related to factors such as the orientation of farmhouses and the heat gain from solar radiation. Research data shows that when the window-towall area ratio of a farmhouse is $30 \%$, the air-conditioning load of the east-west room is $24 \%$ to $26 \%$ larger than that of the south-facing room. Therefore, east-west air-conditioned rooms should be avoided as much as possible in the layout design of farmhouses to promote effective energy conservation [10].

\subsection{The Impact of Natural Ventilation on Energy Consumption} and Reasonable Planning. In spring and autumn, the effective use of natural ventilation can save equipment energy and improve the thermal comfort environment in the farmhouse. At night in summer, the effective organization of natural ventilation can introduce cold outside air. On the one hand, it reduces the cooling energy consumption inside the farmhouse at night, and on the other hand, it can also avoid excessive heat storage on the walls and roof, creating conditions for a cool indoor environment during the next day.

\subsection{The Impact of Greening the Environment on Energy} Consumption and Reasonable Planning. In Chongqing, summer temperatures are high, humidity is high, wind speed is low, and the climate is muggy. Comprehensive heat protection planning measures should be adopted for farmhouses, including the strengthening of the envelope structure, especially the thermal insulation effect of the roof and the west facade. Ensure the natural ventilation of the room. And do a good job of window shading. Practice has shown that suitable planning and layout of green landscape can effectively improve the thermal environment and reduce the impact of outdoor heat on farmhouses. The general greening landscape of farmhouses mainly includes two categories: courtyard greening and wall greening (Figure 2) [11].

The greening of the courtyard can effectively heat insulation. First, trees absorb solar radiant heat and absorb water from the roots to evaporate through the leaves, thereby reducing the air temperature. Secondly, lush trees have a good shading effect in summer. According to statistics, it can block $50 \%-90 \%$ of solar radiant heat. At the same time, because the ground is shady, the heat radiated from the ground to the farmhouse is also reduced. Therefore, the surface temperature and indoor temperature of the farmhouse shaded by trees will decrease. Thirdly, trees also have the function of guiding and blocking the wind. Proper planting can effectively improve the indoor and outdoor thermal environment.

In terms of wall greening, Chongqing is suitable for planting wall climbing plants such as creeper and ivy. In addition, climbing plants such as grapes, melons, beans, morning glory, wisteria, firecrackers, or coral vines are also suitable for planting. These plants grow luxuriantly in summer and are used to block solar radiation and absorb solar heat. In winter, plants will shed their leaves and will not prevent the farmhouse from receiving sunlight. Set up a 


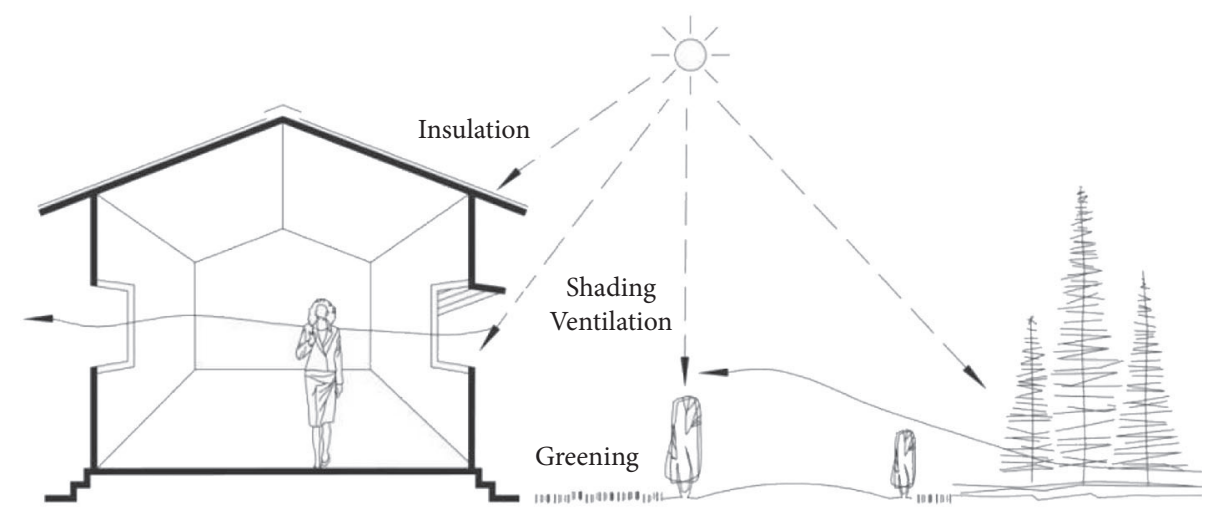

FIGURE 2: Schematic diagram of comprehensive heat protection planning for farmhouses. Chart source: the authors, organized according to relevant data.

scaffold in front of the door, window, or balcony of the farmhouse, so that the climbing plants can grow on the frame, which can form a baffle or horizontal shading. According to statistics, this method of shading can reduce the temperature of the outer surface of the wall by $4-5$ degrees Celsius in the summer season. The indoor temperature can also be reduced by about 1 degree Celsius [12].

\section{Energy-Saving Design of Farmhouses Adapted to the Season}

The energy-saving design of the residential environment of Chongqing's farmhouses uses more energy-efficient materials and electrical equipment in the design of farmhouses to improve the thermal insulation performance of the envelope structure and the energy efficiency ratio of heating and airconditioning equipment. In this way, the energy consumption of heating, cooling, lighting, and other aspects in the use of farmhouses can be reduced. Ultimately improve energy efficiency. Summer is generally hotter in rural areas of Chongqing. In winter, the indoor temperature is low, and energy consumption mainly occurs in these two periods. Therefore, the guiding design of heating and heat preservation in winter and cooling and heat insulation in summer are the core tasks of the energy-saving planning and design of the residential environment of rural houses in Chongqing.

4.1. Energy-Saving in the Residential Environment of Farmhouses in Winter. The rural areas of Chongqing cover hot summers and cold winters, hot summers and warm winters, and mild areas. It is a nonuniform heating area. In winter, rural farmhouses often use the combined effect of household heating equipment such as electric heaters, other heat-receiving equipment, and envelope structure to keep the indoor environment at a suitable temperature. Due to the objective existence of indoor and outdoor temperature differences, heat will inevitably flow from a higher-temperature indoor environment to a lower-temperature outdoor environment, and heat loss will occur through structural parts such as doors, windows, and enclosure structures.
In winter, the overall gains and losses of the farmhouse living environment have a relatively stable structure. When the total gain and loss of the indoor environment of the farmhouse reach a balance, the room temperature can be maintained. Therefore, the main way to save heating energy consumption in farmhouses in winter is to reduce the overall external surface area of farmhouses as much as possible. Improve the thermal insulation performance and air tightness of structural parts such as walls, roofs, doors, and windows. Reduce the heat loss of the enclosure structure of the farmhouse and the air infiltration part in the heat transfer process in order to make full use of the heat gained from the internal environment of the farmhouse and the heat gained by solar radiation. In the specific planning and design, it can be further summarized as optimizing the body shape coefficient, reasonably selecting the types of doors and windows, and applying thermal insulation walls in order to effectively solve the condensation problem [13].

4.1.1. Optimization of the Body Shape Coefficient. The larger the area of the enclosure structure that participates in heat transfer, the greater the heat transfer and heat loss of the rural residential environment. Flat facades and complex farmhouses are not conducive to energy conservation due to their larger envelope structure area. However, farmhouses with regular flat facades, simple shapes, and small body coefficients are beneficial to energy conservation. Therefore, it is necessary to optimize the design of the shape of the farmhouse to reduce the convexity and concavity of the shape of the farmhouse, so as to reduce the body shape coefficient, reduce heat loss in winter, and save energy. Based on the experience of hot summer and cold winter regions, the shape coefficient of rural houses in Chongqing can be controlled within 0.35.

4.1.2. Selection of Door and Window Types. The airtightness and thermal insulation of doors and windows will greatly affect the heating energy consumption of the residential environment. In residential buildings, the heat loss of heat transfer through doors and windows is added to the heat loss of air infiltration, accounting for about $50 \%$ of the total loss. Among them, heat transfer and air infiltration account for 
about half. However, traditional steel windows in rural farmhouses have poor performance in these two aspects, causing a waste of energy. In recent years, new types of doors and windows such as plastic steel doors and windows with good heat preservation and air tightness, single-frame double glass color plate steel windows and aluminum alloy windows have emerged. It has a significant effect on saving heating energy consumption, which can be selected according to the actual situation. In addition, according to the economic situation of different regions, you can choose more economical sealing strips to fill the gaps between doors and windows, or replace with single and double insulating glass with better airtight and heat preservation.

4.1.3. Application of the Thermal Insulation Wall. The exterior walls of rural houses in Chongqing are mostly built with traditional materials such as clay bricks and concrete blocks, which have poor thermal insulation performance. The current technology mature, economical, and reliable thermal insulation wall includes two categories: singlematerial thermal insulation wall and composite thermal insulation wall. The single-material thermal insulation wall adopts a single material with good thermal insulation performance, such as aerated concrete blocks and other masonry walls, without additional thermal insulation. Therefore, the process is simple and the cost is saved. The composite thermal insulation wall is a composite thermal insulation material added to the structural wall, which can be subdivided into external wall internal thermal insulation practices, external wall thermal insulation practices, and sandwich thermal insulation practices.

4.1.4. Solving the Problem of Condensation. The exterior walls and roofs of farmhouses in Chongqing are generally thin, and there are many obvious thermal bridges. Condensation in winter is quite common, which seriously affects farmers' daily life and health. On the one hand, the cause of condensation is due to the low room temperature and the high humidity of the indoor environment due to the closed doors and windows of residents. On the other hand, because there is no central heating in Chongqing, the uneven temperature difference is caused by the use of equipment for heating. Condensation can be avoided by strengthening the thermal insulation of the thermal bridge, adding thermal insulation materials to the ground and external walls, using double-layer glass and thermal insulation doors and windows, and improving the room temperature and humidity. In the dew-condensed farmhouse, the thermal insulation performance of the enclosure structure can be improved by replacing the windows and applying thermal insulation mortar on the inside of the outer wall, so as to alleviate the problem of condensation [14].

4.2. Summer Energy Saving in the Residential Environment of Farmhouses. With the improvement of the living standards of rural residents and the full coverage of Chongqing's rural power grid transformation, the utilization rate of air- conditioning has increased year by year. The key task of energy-saving in summer in the residential environment of farmhouses is to optimize the enclosure structure and effectively save energy consumption of air-conditioning.

4.2.1. Ways for Save Air-Conditioning Energy Consumption in Summer. The ways to save air-conditioning energy consumption in the residential environment of rural houses in Chongqing in summer include adopting an appropriate indoor temperature, using energy-saving air-conditioning equipment with low power consumption in combination with national subsidy policies, choosing energy-saving appliances and lamps and reduce the room temperature by improving the kitchen's heat dissipation performance, and measures such as reasonable layout of air-conditioned rooms. These measures can effectively reduce the external heat gain of the residential environment of the farmhouse and achieve the purpose of saving energy consumption of air-conditioning.

\subsubsection{Wall Structure and Air-Conditioning Energy Saving in} Summer. The wall structure of the farmhouse plays a major role in saving energy consumption of air-conditioning in summer. From the perspective of different number of floors, under the same conditions, the effect of reducing the airconditioning load after increasing the thermal resistance of the outer wall of the top room is more significant. From the perspective of internal and external wall structure, if lightweight materials with lower heat capacity are selected for external walls, the energy-saving effect of air-conditioning will be significant. If heavy materials with higher heat capacity are selected for the inner wall, the indoor heat can be effectively collected and stored, and the energy consumption of the air conditioner can be significantly reduced.

\subsubsection{Farmhouse Doors and Windows and Air-Conditioning} Energy-Saving in Summer. The control of the window area and the window-to-ground ratio, especially the control of the east-west room window-to-ground ratio, can greatly reduce the air-conditioning load and save energy consumption. Window shading facilities, especially those facing west, will have a greater impact on air-conditioning load. This has a major impact on the air-conditioning load. In addition, the air penetration in the room also has a certain impact on the air-conditioning load. In summary, in order to effectively save the energy consumption of farmhouse airconditioning in summer, we should strive to open windows in the north-south direction to reduce the window area and improve its air tightness. In summer, the number of air changes in the room should be reduced.

In addition, take necessary window shading facilities, such as external shading facilities and internal shading facilities. The former shading effect is more remarkable. The latter is widely used because of its convenient construction. Shading facilities can be divided into two categories: fixed shading and movable shading. Fixed sunshades, such as eaves, etc., are neat and beautiful and do not require routine maintenance. Movable awnings, blinds, window shutters, 
and other movable sunshade facilities are all flexibly adjustable. The shading efficiency can reach $100 \%$. It is needed to pay attention to daily maintenance and unified planning. Previous studies have compared the intersubject effect of external sunshades on the indoor natural lighting and building energy consumption of rural residential buildings in Chongqing, that is, the difference $F$ value, to obtain the influence effect degree of sunshades. Based on this, the combination scheme of external sunshade of rural residence in Chongqing is given to meet the natural lighting and reduce air-conditioning energy consumption.

\subsubsection{Selection and Application of Energy-Saving Roofing} Technology. The use of energy-saving roofing technology can effectively insulate and save energy in summer. This applies to the types of rural areas in Chongqing, including reflective roofs, ventilated roofs, ecological green roofs, and water storage roofs.

Reflective roofing is to design the farmhouse roof in white, light gray, and other light colors to reduce solar radiation heat and lower the roof temperature. The internal structure of the ventilated roof is provided with a hollow ventilation layer to take away heat through the wind.

Ecological green roofs can be planted with grass, flowers, shrubs, covering soil planting, and soilless planting in order to effectively reduce solar radiation heat. And radiant heat energy is converted into biological energy and oxygen. Improve the microenvironment (Table 1). Water storage roof is to store a thin layer of water on the roof, use the effect of evaporative heat dissipation to absorb solar radiant heat, and improve the roof thermal insulation capacity. The impounding roof used in some farmhouses in Changhe Village, Luohuang Town, Jiangjin District, Chongqing, has achieved good results. In the construction case of rural residence in Fuling District, Chongqing, the sloping roof with good heat insulation and leakage prevention effect is selected, which has achieved good energy-saving effect.

\section{Effective Utilization of Household Renewable Energy}

Renewable energy is a type of energy that is recycled and inexhaustible. Under the background that national laws and regulations clearly propose to make full use of various types of renewable energy in rural areas, combined with the local characteristics of Chongqing, it is proposed to realize the effective use of renewable energy for households in Chongqing's rural houses from three aspects: biogas, straw energy, and solar energy. This is done to increase the energy flow in the agricultural ecosystem, improve the rural ecological environment and village appearance, and promote the energy-saving and clean energy use of villagers' homes.

\subsection{Effective Utilization of Household Biogas Energy in} Chongqing's Rural Houses. Household biogas is the earliest technical method used for the treatment of household waste in Chongqing's rural households and the production of gas fuel. It has undergone a long-term development process.
Connect the three major links. Involve six major areas (Figure 3). It plays an important role in the coordination of three children in rural areas. After the system and technology are updated, it can be selectively used in suitable rural areas in the future [15].

5.1.1. Construction of the Household Biogas Application System. Chongqing rural household biogas can establish a complete and efficient application system. Five important links are included, including household biogas management and promotion, technical support, financial subsidies, production and operation, and social group services (Figure 4). On July 15, 2021, the Department of Science, Technology and Education of the Ministry of Agriculture and Rural Areas organized an exchange meeting on the investigation and guidance activities of rural biogas safety production. Five investigation and guidance groups made future work ideas, measures and countermeasures for rural household biogas digesters, biogas projects, biogas safety production, and industrial development in 10 provinces and regions such as Chongqing.

5.1.2. Selection and Update of Household Biogas Digesters. According to the characteristics of Chongqing, in addition to centralized biogas supply in mountainous areas, new thermostatic biogas digesters based on renewable energy can also be used in applicable areas. This type of biogas digester can effectively use solar energy to keep the biogas digester at a constant temperature to ensure biogas production. The water can be heated by solar energy to increase the temperature in the pool, or solar radiation can be directly used to increase the temperature in the pool to ensure the normal operation of the biogas digester in winter (Figure 5) $[16,17]$.

5.2. Effective Utilization of Rural Straw Energy in Chongqing. Rural straw yields are relatively high, which can be converted into energy use according to local conditions. For example, the use of biomass conversion technology can increase the thermal efficiency by $35 \%-40 \%$. In this way, waste materials can be fully utilized, and environmental pollution caused by straw incineration can be avoided.

5.2.1. Centralized Gas Supply by Gasification. The mountain villages in Chongqing are relatively scattered in space, the scale of agricultural land is limited, and the straw yield is not high. Household equipment such as a new type of straw gasifier can be used. However, rural areas with relatively flat land and concentrated scale have larger straw yields. It can be used as a raw material to supply gas to farmers through a centralized gas supply method suitable for gasification in Chongqing. Through cooking and other application methods, the original energy consumption structure of farmers based on fuelwood will be improved. The basic model is as follows: set up gasification stations and deliver gas to farmers through the gas pipeline network (Figure 6). The gasification centralized gas supply system uses natural 
TABLE 1: Thermal measured values with and without planting layer.

\begin{tabular}{lcccc}
\hline Project & Unit & No planting layer & Planted roof & Difference value \\
\hline Maximum temperature of the outer surface & Celsius & 61.6 & 29.0 & 32.6 \\
Amplitude of outer surface temperature & Celsius & 24.0 & 1.6 & 3.02 \\
Maximum temperature of the inner surface & Celsius & 32.2 & 1.2 & 2.0 \\
Internal surface temperature fluctuation & Celsius & 1.3 & 0.1 \\
\hline
\end{tabular}

Chart source: the authors, organized according to relevant data.

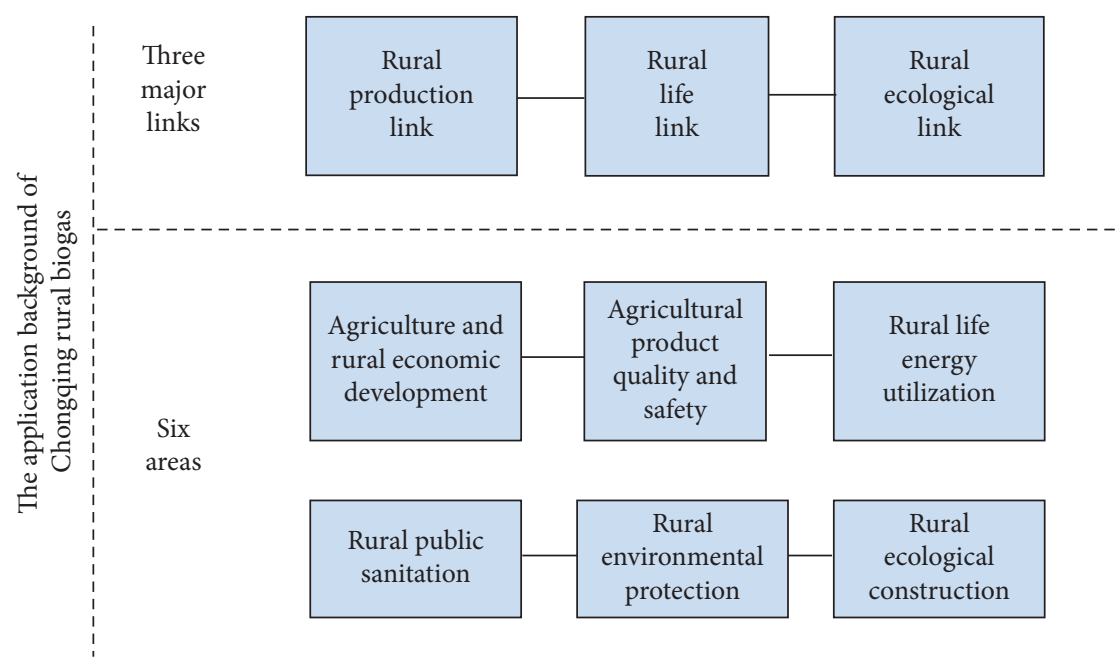

Figure 3: Schematic diagram of the application background of Chongqing rural biogas energy. Chart source: the authors.

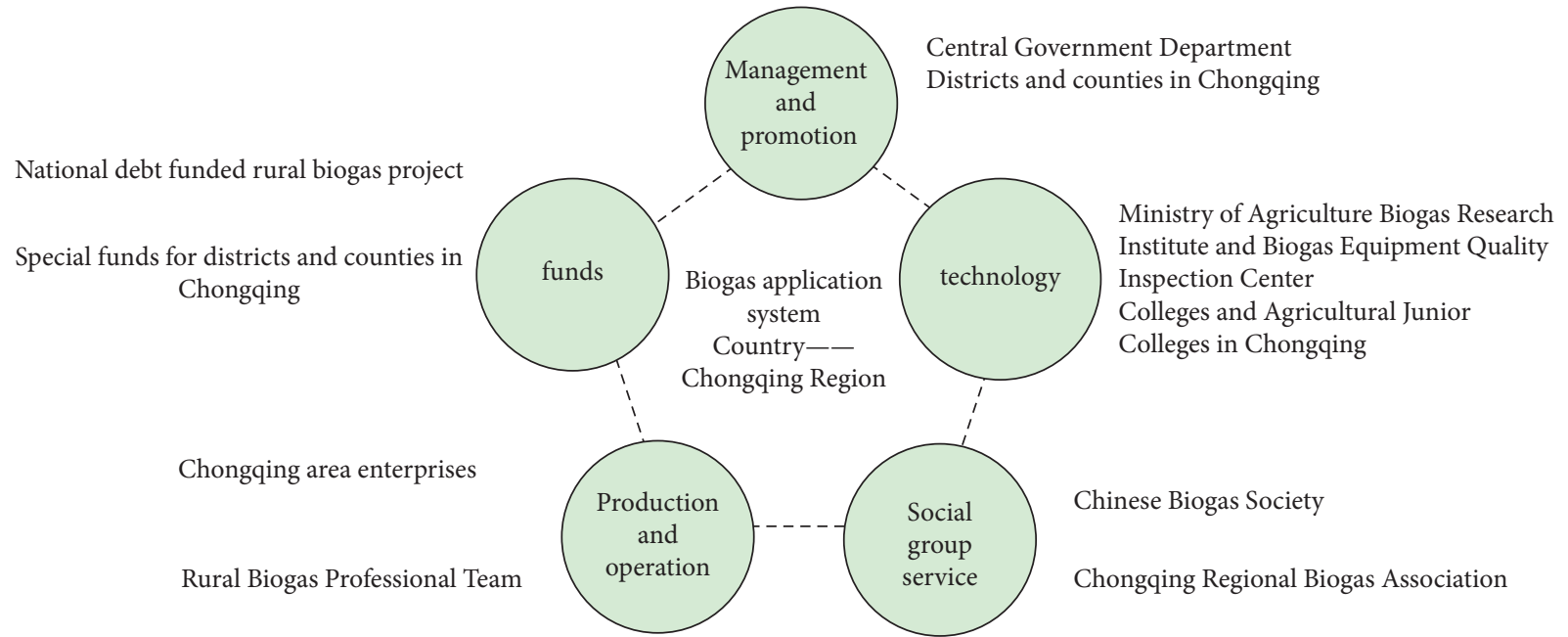

FIGURE 4: "National level-Chongqing area" rural biogas energy application system composition diagram. Chart source: the authors.

villages as the unit, and its gas cost is only $60 \%$ of the liquefied gas [18].

\subsubsection{Application of Gasification Power Generation.} Straw gasification power generation is to convert the biomass energy of straw into heat energy through anoxic combustion to generate combustible gas and drive a steam turbine generator to generate electricity. The current "biomass generator set" with newer technology has improved many disadvantages of the traditional furnace structure. It adopts a new structure of compartmental combustion, which can ensure full combustion of biomass and effectively reduce flue gas emissions, improve heat conversion efficiency, can continuously feed large amounts of materials and generate electricity, and process straw with high efficiency (Figure 7). Same as above, the site selection, scale and construction method of 


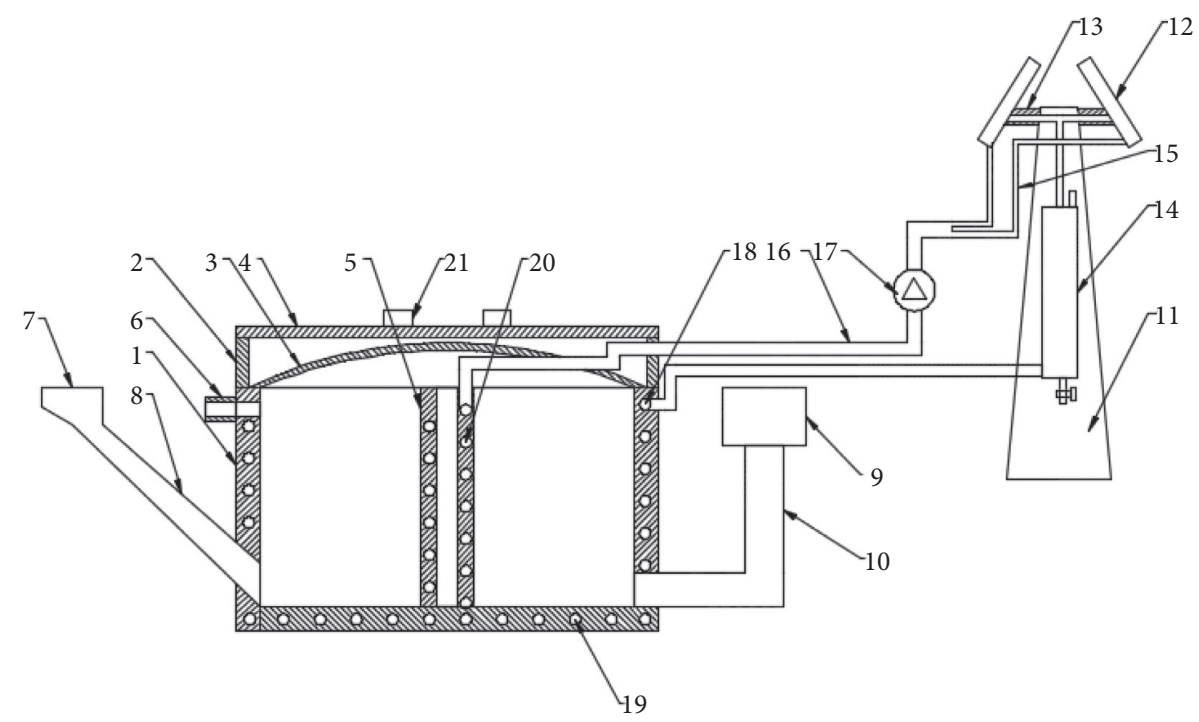

FIGURE 5: Design drawing of a new constant temperature biogas digester based on renewable energy. Chart source: the authors. 1: biogas digester, 2: heightening sealing edge, 3: inner sealing cover, 4: outer sealing cover, 5: central column, 6: biogas outlet pipe, 7: feeding port, 8: feeding pipe, 9: overflow port, 10: overflow pipe, 11: high tower, 12: solar collector, 13: support, 14: insulation water tank, 15: first water pipe, 16: second water pipe, 17: water pump, 18: first heating pipe, 19: second heating pipe, 20: third heating pipe, and 21: handle.

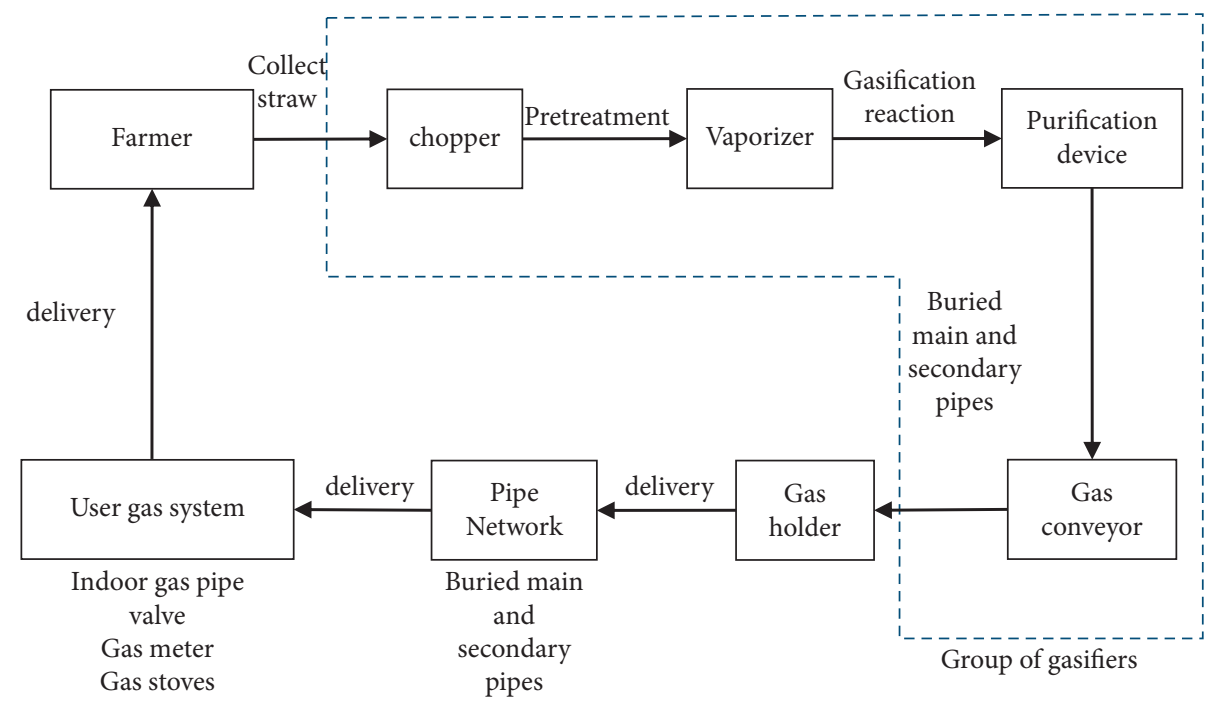

FIgURE 6: Planning flowchart of Chongqing rural straw gasification centralized gas supply mode. Chart source: the authors, organized according to relevant data.

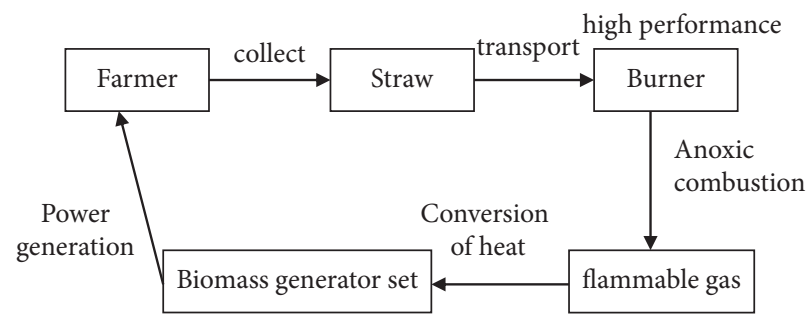

FIGURE 7: Flowchart of the application planning model of Chongqing rural straw gasification power generation. Chart source: the authors.

straw gasification power generation application should also be adapted to the characteristics of Chongqing's rural areas [19]. As early as 2007, the pilot project of straw gasification centralized gas supply has been built in the villages of Yongchuan District and Dianjiang District of Chongqing. 
TABLE 2: Analysis of the distribution and promotion of solar energy resources in southwest China.

\begin{tabular}{|c|c|c|c|c|}
\hline Area category & Solar resource & Southwest region & Daily radiation $\left(\mathrm{kWh} / \mathrm{m}^{2}\right)$ & Solar promotion \\
\hline First category & The richest & Western Tibet & $5.1-6.4$ & \\
\hline Second category & Richer & Southeastern Tibet & $4.5-5.1$ & Suitable for promotion \\
\hline The third category & Medium & Yunnan & $3.8-4.5$ & Solar energy \\
\hline The fourth category & Poor & - & $3.2-3.8$ & \\
\hline The fifth category & Least & Chongqing, Sichuan, Guizhou & $3.2-3.5$ & Partial promotion of solar energy \\
\hline
\end{tabular}

Chart source: the authors, organized according to relevant data.

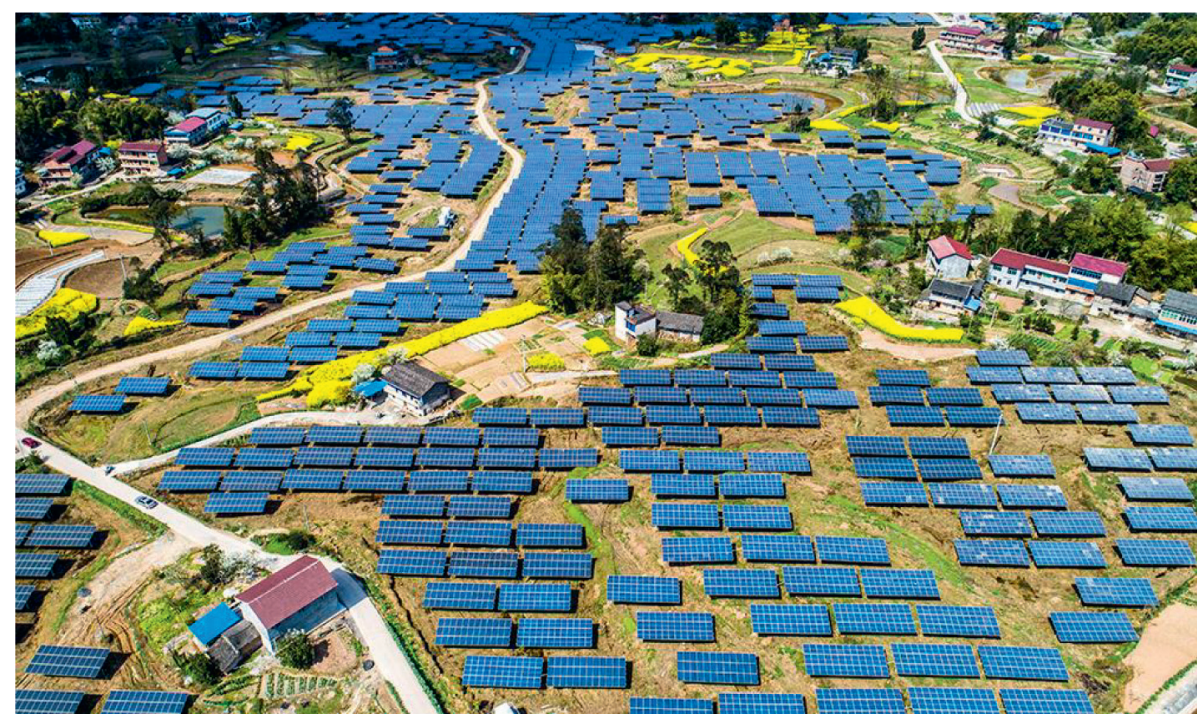

Figure 8: Photovoltaic power generation scene in Bade Village, Bashan Town, Zhong County, Chongqing. Chart source: Xinhua News Agency.

TABle 3: Comparison and analysis table of the advantages of energy storage solar stoves and traditional energy sources.

\begin{tabular}{|c|c|c|c|c|c|c|c|}
\hline Category & $\begin{array}{l}\text { One-time } \\
\text { input cost }\end{array}$ & The cost & $\begin{array}{l}\text { Absolute carbon } \\
\text { emission value }\end{array}$ & Life & $\begin{array}{l}\text { Whether to run } \\
\text { automatically }\end{array}$ & $\begin{array}{c}\text { Whether it has } \\
\text { heat storage } \\
\text { capacity }\end{array}$ & Thermal power \\
\hline $\begin{array}{l}\text { Biomass such as wood, } \\
\text { etc. }\end{array}$ & Low & Low & Zero & $\begin{array}{l}\text { Very } \\
\text { long }\end{array}$ & No & $\begin{array}{l}\text { Yes, stored as } \\
\text { chemical energy }\end{array}$ & Larger \\
\hline $\begin{array}{l}\text { Liquefied petroleum } \\
\text { gas, natural gas, etc. }\end{array}$ & Medium & $\begin{array}{l}\text { Relatively } \\
\text { high }\end{array}$ & High & $\begin{array}{l}\text { Very } \\
\text { long }\end{array}$ & No & $\begin{array}{l}\text { Yes, a chemical } \\
\text { energy storage }\end{array}$ & Larger \\
\hline Electrothermal & Low & $\begin{array}{l}\text { Relatively } \\
\text { high }\end{array}$ & High & $\begin{array}{l}\text { Very } \\
\text { long }\end{array}$ & Yes & No & Smaller \\
\hline $\begin{array}{l}\text { Traditional solar } \\
\text { cooker }\end{array}$ & Medium & Low & Zero & $\begin{array}{l}\text { Very } \\
\text { long }\end{array}$ & No & No & Smaller \\
\hline $\begin{array}{l}\text { Energy storage solar } \\
\text { cooker }\end{array}$ & $\begin{array}{l}\text { Relatively } \\
\text { high }\end{array}$ & Low & Zero & $\begin{array}{l}\text { Very } \\
\text { long }\end{array}$ & Yes & Yes & $\begin{array}{c}\text { Great, direct } \\
\text { heat conduction }\end{array}$ \\
\hline
\end{tabular}

Chart source: the authors, compiled according to "Tibet Department of Agriculture and Animal Husbandry Department. Tibet Rural Household Solar Energy Supply Project Feasibility Report[R] 2015.”

5.3. Effective Use of Solar Energy. The distribution of total solar radiation in the southwest is uneven. There are both high-resource areas and low-resource areas. The daily radiation dose in Chongqing is relatively low (Table 2). However, even in areas with poor solar energy resources, the total solar radiation in some towns and villages is relatively large. As far as a small area is concerned, it is still an area rich in solar energy resources, and the use of solar energy technology can also be promoted. Therefore, the situation of rural solar energy in Chongqing is "if there is more, there will be more usage, and if there is less, there will be less usage." Solar energy should be used effectively according to local conditions(Figure 8).

The solar energy utilization types applicable to rural areas in Chongqing mainly include solar water heaters, solar lights, solar photovoltaics, solar stoves, solar greenhouses, and solar houses. Take Chongqing as an example: farmers in 6 towns including Shuangfeng and Zouma in Hechuan and Wanzhou districts have installed more than 1,600 solar water heaters and achieved good results. Gaofengsi Village, 
Fuling District, located in the Wujiang Gorge, is sunny. Install low-cost independent household solar photovoltaic. The area is about 30 square meters. It can generate 5000 kilowatt-hours of electricity every year. The installation of 200 solar street lights in the high mountain ecological relocation site of Zhongxin Temple in Qianjiang District has effectively improved the lighting environment of the village and saved electricity. Bishan area uses solar greenhouses of flowers, breeding, fruit trees, vegetables, and ecological sightseeing to increase the temperature in the sheds in winter and effectively promote high-value agricultural production activities. In addition, energy storage solar stoves are a new type of combined heat and power system popularized in rural areas in Tibet in recent years. It can automatically complete solar thermal energy collection and storage and electrical energy conversion and storage. The use cost is relatively low, the continuous use time is relatively long, and its thermal power is relatively high. It can be verified to explore the possibility of its application in suitable rural areas in Chongqing (Table 3)[19, 20].

\section{Conclusions and Prospects}

This chapter summarizes the energy-saving design path of rural farmhouses in Chongqing, aiming to enhance the coherence between the artificial construction environment, the natural ecological environment, and the socioeconomic and cultural environment. In view of the author's limited theoretical ability and practical experience, this article only constructs a comprehensive research framework. Its specific research content, research depth and working methods still need to be gradually adjusted and improved in the future study, research and practice process. Looking to the future, there are the following aspects that need attention:

(1) Further regional and targeted research

The geographical features of Chongqing area, such as topography, climatic environment, history and humanities, are more distinctive. The planning methods and actual construction conditions of rural human settlements have their own characteristics. The same applies to the energy-saving design path of farmhouses. Part of the research content in this article still presents universality and generality. The regionality and pertinence can be further strengthened.

(2) Strengthen the in-depth study of the energy-saving design path of rural houses in Chongqing

Part of the theoretical research on the surface and middle level will be promoted to a deeper level. Further strengthen the research work of induction, summary and analysis. Strengthen the logic construction process. Promote the highlights and innovative thinking in theoretical research.

(3) Establish a relevant evaluation system for the energysaving design path of Chongqing's farmhouses

This article puts forward the overall research framework of Chongqing's rural house energy- saving design path and can further try to establish an evaluation system for Chongqing's rural house energy-saving design. With the support of necessary data, various ecological index factors, scoring rules, and weighting basis are set in the evaluation standards. This can more effectively improve the standardization and scientificity of the energy-saving design path of Chongqing's farmhouses and provide a basis for the initiation and evaluation of related construction work.

(4) Strengthen practicality and gradualism

Rural work is a task of "being grounded and alleviating people's worries." This article conducts guided research more from the level of theoretical understanding and guiding path. In the future work, the actual needs of the villagers should be the core, and specific issues should be analyzed in detail, so that theory can be combined with practice. Under the background of the rural revitalization strategy that satisfies the ecological and livable environment, we will better serve the peasants.

\section{Data Availability}

No data were used to support this study.

\section{Conflicts of Interest}

The authors declare that they have no conflicts of interest regarding the publication of this paper.

\section{Acknowledgments}

This work was funded by the Science and Technology Research Project of Chongqing Municipal Education Commission "Research on the Ecological Quality Improvement Technology of Chongqing Farm Houses in the Context of Rural Revitalization" (Project no. KJQN201900740). This work was also supported by the Chongqing Social Science Planning Doctoral Project "Research on the Artistic Reuse Mode of Rural Disused Farmhouse Environment in Chongqing” (no. 2019BS094).

\section{References}

[1] Research Center for Building Energy Efficiency, China Annual Development Research Report on Building Energy Efficiency 2020 (Rural Housing Project), Tsinghua University, Beijing, China, 2020.

[2] Energy Consumption Special Committee of China Building Energy Conservation Association, China Building Energy Consumption Research Report, Energy Consumption Special Committee of China Building Energy Conservation Association, Beijing, China, 2020.

[3] X. Wang and H. Hong, Green Village and Town Construction in China, Springer, Berlin, Germany, 2021.

[4] Y. Yan, W. Jiao, K. Wang, Y. Huang, J. Chen, and Q. Han, "Coal-to-gas heating compensation standard and willingness to make clean energy choices in typical rural areas of northern China," Energy Policy, vol. 145, no. 10, Article ID 111698, 2020. 
[5] Q. Du, X. Han, Y. Li, Z. Li, B. Xia, and X. Guo, "The energy rebound effect of residential buildings: e," Energy Policy, vol. 153, no. 7, Article ID 112235, 2021.

[6] K. O’Sullivan, O. Golubchikov, and A. Mehmood, "Uneven energy transitions: understanding continued energy peripheralization in rural communities," Energy Policy, vol. 138, no. 3, Article ID 111288, 2020.

[7] Z. Hu, "When energy justice encounters authoritarian environmentalism: the case of clean heating energy transitions in rural China," Energy Research \& Social Science, vol. 70, no. 12, Article ID 101771, 2020.

[8] X. Zeng, Y. Zhao, and Z. Cheng, "Development and research of rural renewable energy management and ecological management information system under the background of beautiful rural revitalization strategy," Sustainable Computing: Informatics and Systems, vol. 30, no. 7, Article ID 100553, 2021.

[9] Q. Zhang, M. Luo, and S. Sun, "Research on energy-saving renovation of rural houses in hot summer and cold winter area," Building Energy Efficiency, vol. 1, no. 2, pp. 87-91, 2019.

[10] J. Shi and Q. Li, "Energy saving performance evaluation and planning OptimizationDesign of rural residential building environment," Argos, vol. 36, no. 73, 2019.

[11] D. Li, X. An, and H. Li, "Preliminary study on the energysaving renovation of existing rural houses in hot summer and cold winter areas: taking rural houses in Deyang city, Sichuan province as an example," Building Energy Conservation, vol. 1, no. 4, pp. 87-92, 2020.

[12] C. Jia, A. Feng, Li Zhong et al., "The impact of the renovation of existing farm buildings in southern Fujian on the indoor thermal environment," Building Energy Conservation, vol. 1, no. 1, 2019.

[13] B. Zou and A. K. Mishra, "Appliance usage and choice of energy-efficient appliances: e," Energy Policy, vol. 146, no. 11, Article ID 111800, 2020.

[14] C. Zi, M. Qian, and G. Baozhong, "The consumption patterns and determining factors of rural household energy: a case study of Henan Province in China," Renewable and Sustainable Energy Reviews, vol. 146, no. 8, Article ID 111142, 2021.

[15] H. Roubík and J. Mazancová, "Suitability of small-scale biogas systems based on livestock manure for the rural areas of Sumatra," Environmental Development, vol. 33, no. 3, Article ID 100505, 2020.

[16] J. Shi and Q. Li, "A new type of constant temperature biogas digester based on renewable energy," National Utility Model Patent, 2016.

[17] M. R. Shaibur, H. Husain, and S. H. Arpon, "Utilization of cow dung residues of biogas plant for sustainable development of a rural community," Current Research in Environmental Sustainability, vol. 3, Article ID 100026, 2021.

[18] Z. Liu, M. Wang, Q. Xiong, and C. Liu, "Does centralized residence promote the use of cleaner cooking fuels? evidence from rural China," Energy Economics, vol. 91, no. 9, Article ID 104895, 2020.

[19] F. Huang, Z. Wang, J. Liu, C. Shuai, and W. Li, "Exploring rural energy choice from the perspective of multi-dimensional capabilities: e," Journal of Cleaner Production, vol. 283, no. 2, Article ID 124586, 2021.

[20] O. Kaya, A. M. Klepacka, and W. J. Florkowski, “Achieving renewable energy, climate, and air quality policy goals: rural residential investment in solar panel," Journal of Environmental Management, vol. 248, no. 10, Article ID 109309, 2019. 